\title{
Intuition, a Part of Bipolar Disorder? The Emotional Brain-Survival and Time
}

\author{
Einar Hellbom* \\ Email: einarhellbom@yahoo.com
}

Received 25 February 2014; revised 30 March 2014; accepted 8 April 2014

Copyright (C) 2014 by author and Scientific Research Publishing Inc. This work is licensed under the Creative Commons Attribution International License (CC BY). http://creativecommons.org/licenses/by/4.0/

\begin{abstract}
Survival and reproduction are essential for all living forms. Can intuition increase the survival rate and be a part of the evolution? One of our survival functions is the automatic response to fear like our reaction to snakes mediated by the amygdala also called the emotional brain. But how fast can the amygdala react? Can it react and protect even before an event has occurred? Dreams and visions bringing warnings of future danger have been described by many people. The condition can be related to psychiatric disorders and have a genetic base. If we strictly follow Einstein's general theory, time is a dimension containing our universe's past and future at the same time. Then a "time mirage" can be like an optical mirage where you can see people in the desert but they cannot see you. Our methods of measuring this dimension are limiting our understanding of it; but if the brain has access to the dimension, we might be able to study and understand it better with new tests.
\end{abstract}

\section{Keywords}

Emotion, Evolution, Amygdala, Bipolar, Intuition, Precognition, Time

\section{Creativity and Psychiatric Disorders}

In October 1913 Carl Jung was afraid he was going insane. He had a vision of the map of Europe covered with water turning into blood all the way up to Switzerland where the Alps protected the country from being flooded. In August 1914, when the First World War began, he realized that it was a precognition (Jung, 1963). What happened in Jung's brain? He had a vision about the future and he remembered it as a memory of the future. If precognition was possible, it would certainly be a great survival advantage that could be common in other species as well. If this is true, the system is probably built in our brains to warn for future dangers or to find a partner, a survival and reproduction system extended in time in amygdala, also called "the emotional brain” by Le-

\footnotetext{
*Independent author.
} 
Doux (LeDoux, 2012). Strong emotions can probably also activate the system like love or depression, a disease with high mortality, but direct fear of life must be the strongest.

If you can be warned months ahead, how fast can you react to dangers? Charles Darwin tested his free will in 1838 when he visited the new London Zoo. He pressed his face against the glass at the puff-adders cave, determined not to be afraid, but jumped back automatically when the snake attempted to strike (Darwin, 1872). In the cases where your life is threatened, the amygdala overrules your free will. We do not know how fast Darwin reacted, but if he reacted even a split second before the snake actually struck, it would have saved his life in the wild.

An overly active fear system can also be a problem, like living in a house where the fire alarm will activate every time you make a cup of tea. We can have a fear of the future disturbing our life through panic and anxiety, lowering our ability in daily life and negative in evolution.

This sensitivity can be a form of psychiatric disorders common in creative professions and artistic occupations confirmed in large studies by Kyaga, S., et al. in a sample of 1,173,763 patients (Kyaga et al., 2013) and Power, R., et al. in 2.3 million individuals in Sweden (Power et al., 2013). The studies defy the expectations of natural selection. Creativity can be one factor but if warnings of future dangers and death intuition/precognition exist in the family; the survival can compensate and be a part of the balancing selection hypothesis by Huxley, J., et al. (Huxley et al., 1964).

Creativity in music has been reported genetic (GALM at2p22) for serotonin release and transport both for music and psychiatric disorder. Even the gene for absolute pinch found only in $1-10.000$ has been identified (Ukkola-Vuoti et al., 2013). It is possible that people reporting paranormal warnings of the future can belong to a genetic group and share the gifts and disadvantages of it, like the genes found for music.

The use of not only drum music by shamans but also many substances in nature like psilocybin, mescaline and other acting on serotonin, dopamine or other receptors can increase emotions and fear and stimulate their contacts in another reality. Today Jung's psychotic visions would have been "cured" by a neuroleptic treatment. If a patient reports something like a "Jung syndrome", a careful report should be written to document the delusions, and if possible a genetic test should be done to see if special genes can be found.

Those hoping to find a system to see the future in lottery or horse racing can speak to all ruined gamblers to understand that it will fail.

This is probably a warning-system to save life, not to reward gambling.

\section{Research in the Field}

Presently, the amount research in this field is low, as too many case reports are neglected and too few studies are confirmed. The most solid study was done by Moulton and Kosslyn using fMRI, however it cannot detect any psi-parapsychological activity in the brain (Moulton \& Kosslyn, 2008). The problem is that the amygdala cannot be studied effectively by fMRI because it is too close to bone structures. However, this study is still of great value since we now have one area, the amygdala, the emotional brain, to study more carefully. For amygdala studies we will have to also resort to older methods. Studying reactions to snakes and angry faces, as discussed by Ohman (Ohman, 2009), has been used in psi-precognition tests by Radin, Borges and Bem using erotic or negative stimuli to be predicted before the computer randomly selected the photo as a test of precognition (Radin \& Borges, 2009) (Bem, 2011). The tests have been criticized from various points and the field is still open. The large metastudy by Mossbridge et al. of video game players at work that often can feel the fear for the boss coming closer in time to react and go back to work is in line with the subconscious warning system (Mossbridge et al., 2012).

The question is, can we find better tests? And can animals be used or must we use humans? For animal tests we have the Alvarez study of Zebra Finches reaction to video clips of snakes in which the finches reacted before they saw the snakes (Alvarez, 2010). Small birds can fly over dark continents guided by stars or magnetic fields to save their lives, intuition encoded in their genes is saving them from death in cold.

Since so many precognitive dreams are reported, dreams can be a natural way without drugs to open the door to time for answers or warnings. With all these case reports we can ask why not even more are reported. An explanation can be that even if you do have this "gift" it must also be activated by a future danger, and therefore we have all the case reports like Dunne, J. W. (Dunne, 1927) or Rhine, L. E. (Rhine, 1969) and other papers. We are not so often exposed to deadly dangers except in war in our modern lives. Tests for precognition with neutral 
cards have been used for many years by Rhine, J. B. (Rhine, 1975) and the reliability of these tests has been discussed. Testing the "emotional brain" with neutral cards might not awake emotions. Snakes, sinister-looking faces or attractive potential partners for young students are more likely to activate them.

\section{New Forms of Tests}

For future tests we can use different methods. One possibility is to use controlled computer games. Young people at their peak hormonal level and eager to fight virtually can be introduced to games where choosing the wrong road might a few seconds later kill the virtual soldier. If the virtual danger can activate the players fear system it can save their virtual soldier. The fear reaction is vital. All followed by fMRI activity in the brain. This could be a possible test of fear-activated precognition without risking lives.

Also the studies by Haynes (Haynes, 2011) on the several seconds long reaction time in the brain can be tested in computer games of fast sports where reaction time is vital. Can you react before time or before making up your mind? Can the amygdala take over automatically and act faster not only in danger but also in sport games?

It is also possible to use an HSP test like Aron \& Aron (Aron \& Aron, 1997) to find sensitive subgroups for future studies. If other tests also confirm sensitivity the possibility is that even a more specific group can be selected. The use of the therapy REST, floating feeling almost free from gravity and at rest from sensory stimulations, can also be tried to create a "timeless" feeling and for some perhaps a shaman-like situation, a test for possible precognitions without drugs, Kjellgren et al. (Kjellgren et al., 2009-2010).

Maybe genetic tests can find a sensitive intuition/precognition group, so research in the area can be done more easily. If we can use blood samples to find genes for absolute pinch we might be able to find the genes for intuition and precognition if they exist In the bipolar group it might be possible to find some genetic material Testing a small number of "gifted" seers for precognition can give better results than testing 10.000 without the ability and give vital information for future. The genes of Carl Jung had been perfect.

\section{Discussions about Time}

In studying ways to test precognition we must also discuss time.

The time in our space should not to be confused with the dimension of time. We can see an optical mirage in the desert but are unable to talk or act in the mirage since we are not present in space. This was regarded as magic before we know the physical explanation. If we have a "time mirage" our brain will see it but we will not be able to act or speak since it is a mirage and we are not present in space or time. It is impossible to go back and kill your grandfather since you are not present in his space and time dimension. Even photon pairs behave strange since they are in contact without delay with each other faster than light via "the common unconsciousness of photons" or the time dimension probably.

Time and space are better discussed by astrophysicists like Krauss in "A Universe from Nothing” (Krauss, 2012). The Big Bang theory is not very old and only a few years ago we did not know that our universe was expanding and that the Dark energy is counteracting the gravity in our universe. Time seems to be glued to gravity, if they are not the same thing. The stronger gravity the more the time is glued. If you travel in a spaceship at high speed away from the earth gravity you live in another time, your clock will slow down and your old grandchildren will meet you when you return. To explain the strange hypothesis we can use the freedom of authors like Lewis Carrol (who was also a mathematician) and his Alice in "Though the Looking Glass" where she speaks to the White Queen. This was one of Jung's favourite quotes and has also been quoted by Bem. In the book, Alice can only remember backwards where time is running forwards but the White Queen can remember both forwards where time is running backwards and backwards where time is running forwards (Carrol, 1871). If Dark energy can counteract gravity and finally empty our universe of gravity, it will stop the arrow of time and it will be the end for Einstein's universe (Einstein, 1916) and a start of The White Queen's universe, where time runs backwards to the place it came from.

This is an interesting universe not contradicting the present laws of physics. By studying the time dimension we will know more about its nature. It is possible it has a mathematical form as discussed by Tegmark, an algorithm containing unlimited amounts of information about all the present, past and future in eternity, or something beyond our imagination and perception (Tegmark, 2008). 


\section{Conclusion}

The reports of intuition/precognition have followed us from ancient times to modern day. Still the existence of "seeing” or "feeling" the future also called intuition or precognition has not been solidly documented. Using new tests in computer games and finding the genetic background for warnings ahead of time if they exist can confirm the hypotheses. If the genes and receptors can be found, it will be possible to block or stimulate the effect with drugs in new studies. Testing the hypothesis of time by reaction to fear as a survival function can open an interesting future for research.

\section{References}

Alvarez, F. (2010). Anticipatory Alarm Behavior in Bengalese Finches. Journal of Scientific Exploration, 24, 599-610.

Aron, E. N., \& Aron, A. (1997). Sensory-Processing Sensitivity and Its Relation to Introversion and Emotionality. Journal of Personality and Social Psychology, 73, 345-347. http://dx.doi.org/10.1037/0022-3514.73.2.345

Bem, J. B. (2011). Feeling the Future: Experimental Evidence for Anomalous Retroactive Influences on Cognition and Affect. Journal of Personality and Social Psychology, 100, 407-425. http://dx.doi.org/10.1037/a0021524

Carrol, L. (1871). Through the Looking Glass.

Darwin, C. (1872). The Expressions of Man and Animal.

Dunne, J. W. (1927). An Experiment with Time.

Einstein, A. (1916). General Theory. Annals of Physics, 49, 769-820. http://dx.doi.org/10.1002/andp.19163540702

Haynes, J. D. (2011). Decoding and Predicting Intentions. Annals of the New York Academy of Sciences, 1224, 9-21.

Huxley, J., Mayr, E., Osmond, H., \& Hoffer, A. (1964). Schizophrenia as a Genetic Morphism. Nature, 204, $220-221$. http://dx.doi.org/10.1038/204220a0

Jung, C. (1963). Memories, Dreams, Reflections.

Kjellgren, A., Lindahl, A., \& Norlander, T. (2009-2010). Altred States of Consciousness and Mystical Experiences during Sensory Isolation in Flotation Tank: Is the Highly Sensitive Personality Variable of Importance? Imagination, Cognition and Personality, 29, 135-146. http://dx.doi.org/10.2190/IC.29.2.d

Krauss, L. (2012). A Universe from Nothing.

Kyaga, S., Landen, M., Boman, M., Hultman, C. M., Langstrom, N., \& Lichtenstein, P. (2013). Mental Illness, Suicide and Creativity: 40-Year Prospective Total Population Study. Journal of Psychiatric Research, 47, 83-90. http://dx.doi.org/10.1016/j.jpsychires.2012.09.010

LeDoux, E. J. (2012). Evolution of Human Emotion: A View through Fear. Progress in Brain Research, 195, 431-442. http://dx.doi.org/10.1016/B978-0-444-53860-4.00021-0

Mossbridge, J., Tressoldi, P., \& Utts, J. (2012). Predictive Physiological Anticipation Preceding Seemingly Unpredictable Stimuli: A Meta-Analysis. Frontiers in Psychology, 3, 1-8.

Moulton, S. T., \& Kosslyn, S. M. (2008). Using Neuroimaging to Resolve the Psi Demate. Journal of Cognitive Neuroscience, 20, 182-192. http://dx.doi.org/10.1162/jocn.2008.20009

Ohman, A. (2009). Of Snakes and Faces: An Evolutionary Perspective on the Psychology of Fear. Scandinavian Journal of Psychology, 50, 543-552. http://dx.doi.org/10.1111/j.1467-9450.2009.00784.x

Power, R. A., Kyaga, S., Uher, R., MacCabe, J. H., Langstrom, N., Landen, M., McGuffin, P., Lewis, C. M., Lichtenstein, P., \& Svensson, A. C. (2013). Fecundity of Patients with Schizophrenia, Autism, Bipolar Disorder, Depression, Anorexia Nervosa, or Substance Abuse vs Their Unaffected Siblings. JAMA Psychiatry, 70, 22-30. http://dx.doi.org/10.1001/jamapsychiatry.2013.268

Radin, D., \& Borges, A. (2009). Intuition through Time: What Does the Seer See? Explore New York, 5, $200-211$.

Rhine, L. E. (1969). Case Study Review. The Journal of Parapsychology, 33, 228-266.

Rhine, J. B. (1975). Psi Methods Reexamined. The Journal of Parapsychology, 39, 38-58.

Tegmark, M. (2008). The Mathematical Universe. Foundations of Physics, 38, 101-150. http://dx.doi.org/10.1007/s10701-007-9186-9

Ukkola-Vuoti, L., Kanduri, C., Oikkonen, J., Buck, G., Blancher, C., Raijas, P., Lahdesmali, H., \& Javela, J. (2013). Genome-Wide Copy Number Variation Analysis in Extended Families and Unrelated Individuals Characterized for Musical Aptitude and Creativity in Music. PLoS ONE, 8, e56356. http://dx.doi.org/10.1371/journal.pone.0056356 